\title{
A APLICAÇÃO DA PENA NO SISTEMA PENAL BRASILEIRO: A CULPABILIDADE COMO ELEMENTO CENTRAL DE VALORAÇÃO.
}

\section{SANCTION APPLICATION IN THE BRAZILIAN PENAL SYSTEM: GUILT AS PRINCIAL ELEMENT OF VALUATION}

\section{Leonardo Henrique Gonçalves de Siqueira ${ }^{1}$}

Resumo: O presente artigo investiga a relação entre culpabilidade e medida da pena dentro do ordenamento jurídico brasileiro, especialmente no momento de fixar a pena-base. A situação se dificulta quando percebemos, conforme doutrina de Hungria, que o nosso atual artigo 59 do código penal agrega pressupostos da Escola Clássica e da Escola Positivista. A falta de técnica legislativa permitiu legitimar sentenças criminais que mediram a pena levando em relevo elementos relacionados ao modo de ser do agente, o que fere os ditames de um Estado Democrático de Direito.

Palavras-chave: CULPABILIDADE. MEDIDA DA PENA. ESCOLA CLÁSSICA. ESCOLA POSITIVA

\begin{abstract}
This paper investigates the relationship between culpability and measure of sanction within the Brazilian legal system , especially at the time of fixing the base sanction. The situation is difficult when we realize, as the doctrine of Hungria , that our current Article 59 of the penal code adds assumptions of Classical School and the Positivist School. The lack of legislative technique allowed legitimize criminal sentences that measured the sanction taking into account elements related to the mode of being of the agent, which hurts the assumptions of a democratic state .
\end{abstract}

Keywords: CULPABILITY. MEASURE OF SANCTION. CLASSICAL SCHOOL. POSITIVIST SCHOOL

\footnotetext{
1 Doutor em Direito pela Universidade Federal de Pernambuco. Professor da Faculdade Damas da Instrução Cristã de Pernambuco, Recife, Pernambuco, Brasil.
} 


\section{INTRODUÇÃO}

Normalmente, quando relacionamos um sistema punitivo inserido num Estado que se assuma como Democrático e de Direito, pensamos primeiramente na Legalidade. Todavia, essa adequação do direito penal aos ditames do Estado Democrático de Direito não encerrar as suas pretensões garantistas no Princípio da Legalidade, tendo em vista que, no momento da aplicação da pena, temos inúmeras sentenças inconstitucionais, inclusive algumas violam princípios constitucionais penais.

Nesse caminho, podemos dizer que o mais importante princípio constitucional violado nas decisões judiciais é o da Culpabilidade, que exige uma pena privativa de liberdade adequada a culpabilidade do autor do fato típico e ilícito ${ }^{2}$. Sem dúvida motivados pela equivocada interpretação que grande parte da doutrina comunga em relação às circunstâncias judiciais do artigo 59, os julgadores não fixam a pena em consonância com a culpabilidade, pois esta é vista apenas como mais uma circunstância a ser ponderada dentre as demais constantes no citado artigo. E isso, sem dúvida alguma, leva a penas desproporcionais e em desconformidade com a culpabilidade do agente.

A necessidade de fundamentação idônea, que é outro imperativo de sede constitucional, não abarca somente o mérito da ação penal(condenando ou inocentando), uma vez que a dosimetria da pena, principalmente no exame das circunstâncias do artigo 59 do código penal brasileiro, constitui uma fase imprescindível da sentença condenatória, merecendo em todos os casos uma fundamentação coerente e de acordo com os ditames de um direito penal garantista. A necessidade de fundamentação ainda é importante por ser um aspecto fundamental na concretização da ampla defesa e do contraditório, pois a possibilidade de recorrer de uma sentença só existe quando os argumentos judiciais utilizados na decisão estão claramente expostos. Só dessa forma podemos falar em contraditar os fundamentos da decisão e possibilitar uma nova discussão e um novo julgamento.

Por outro lado, a discussão aqui travada se limita apenas a um lado do problema, uma vez que iremos focar na problemática construção do artigo 59 do nosso código penal. Não podemos negar que partimos do pressuposto - que não será discutido no presente artigo - que a culpabilidade deve ser o elemento norteador do juiz no momento de aplicar a quantidade de pena. Assim, a sempre precisa lição de Nélson Hungria deve ser a primeira a examinarmos.

\footnotetext{
${ }^{2}$ SCHÜNEMANN, Bernd. La función del principio de culpabilidad en el derecho penal preventivo. In: SCHÜNEMANN, Bernd (Org.). El sistema moderno del derecho penal: cuestiones fundamentales. Buenos Aires: BdeF, 2012, p. 183.
} 
Segundo o autor a individualização da pena, na sua primeira fase, seria uma união pragmática entre a escola clássica e positivista, ou seja, seria a conciliação póstuma entre Carrara e Ferri ${ }^{3}$, que são os maiores expoentes das escolas citadas. $\mathrm{O}$ autor teve o mérito de perceber que essa composição seria inconciliável do ponto de vista metodológico, desvelando problemas graves no momento da fundamentação das circunstâncias judiciais do artigo em comento, o que acarreta, na maioria das vezes, uma pena desproporcional a culpabilidade do agente.

Ante a argumentação de Hungria, começaremos pelo exame dos principais pressupostos das escolas citadas, o que dará o embasamento para discutirmos os principais problemas relacionados as circunstâncias judiciais do artigo 59 do código penal.

\section{O EMBATE ENTRE A ESCOLA CLÁSSICA E A ESCOLA DO POSITIVISMO CRIMINOLÓGICO: A QUESTÃO DA RESPONSABILIDADE CRIMINAL E A MEDIDA DA PENA.}

Não é novidade que a escola clássica e a positiva possuem diferenças marcantes, mormente quanto ao método adotado, visto que os autores clássicos adotam o método dedutivo com todas as suas implicações, e os positivistas, inovando no exame das questões penais, seguem os ditames do método indutivo a partir de uma observação controlada dos fatos.

Nesse sentido, a escola clássica entende o crime como um ente abstrato, para ficarmos na acepção de Carrara, que precisa ser examinado e decomposto em elementos - chamados pelo autor como as forças do delito -, a partir do método dedutivo ${ }^{4}$. Nessa análise ganha especial relevo, como base da responsabilidade criminal, a ideia do livre arbítrio, que guarda uma intima relação com a quantificação da pena.

Para o autor, o indivíduo só pode ser responsabilizado criminalmente se for dotado de liberdade de escolha. Em termos modernos podemos dizer que, para o autor italiano, a aplicação de uma pena depende e se mede a partir do exame da reprovação pessoal que se deve fazer sobre o agente que comete o fato delituoso, quer dizer, com base na sua culpabilidade $^{5}$. Por esse motivo, o autor estuda detidamente as causas que poderiam levar a

\footnotetext{
${ }^{3}$ HUNGRIA, Nelson. Comentários ao código penal. Rio de Janeiro: Revista Forense, 1955, vol V, p. 447.

${ }^{4}$ CARRARA, Francesco. Programma del Corso di Diritto Criminale: Parte Generale. Lucca: Tipografia Giusti, 1889, vol. I, p.27-28 .

${ }^{5}$ A obra de Carrara pode ser considerada um marco dentro do desenvolvimento da dogmática penal, pois, pela primeira vez, temos um desenvolvimento da teoria do crime dentro dos parâmetros analíticos que hoje desenvolvemos e conhecemos muito bem. Sem dúvida, é uma obra que denota um grande esforço de sistematização do direito penal, o que engrandece ainda mais a obra do mestre italiano.
} 
exclusão ou atenuação da força moral - culpabilidade em termos modernos -, refletindo diretamente na aplicação da pena, como, por exemplo, nos casos de obediência hierárquica, embriaguez, surdo-mudez, sexo, sono, loucura e, por fim, em virtude de um fator ideológico, o erro ${ }^{6}$.

A influência de Carrara é tamanha quando pensamos nessa relação entre crime e pena, pois, modernamente, Zaffaroni, por exemplo, defende que a culpabilidade é a conexão punitiva que liga a teoria do delito a da pena, sendo esta medida na razão da culpabilidade do agente $^{7}$. Nesse sentido, o artigo 59 do CP estabelece principalmente a culpabilidade como uma circunstância judicial a ser levada em consideração no momento da fixação da pena.

Por outro lado, a escola do positivismo criminológico tem no método indutivo a sua principal característica, ou seja, a criação de leis gerais e abstratas só surgiria depois de uma minuciosa e controlada observação dos fatos, que os permitia - pelo menos era assim que eles acreditavam - um exame efetivo da realidade, saindo da abstração gerada pelos adeptos da escola clássica.

Especificamente em relação ao direito penal, acreditava-se que era necessário examinar a realidade social e, consequentemente, focar os estudos no homem que cometeu o delito(criminoso $)^{8}$, em detrimento a análise do crime como um ente abstrato, que nada informaria sobre o homem delinquente ${ }^{9}$.

Essa nova forma de se pensar o direito penal teve - e ainda tem - grande influência na visão sobre o crime e, consequentemente, na medida da pena. O fenômeno da criminalidade passa a ser observado sob uma nova ótica, onde o crime passa a ter importância secundária em relação ao indivíduo que o comete. Essa nova lente busca identificar o delito como expressão da personalidade e da periculosidade do criminoso $^{10}$. Por conseguinte, fica claro que a medida da pena não se relaciona mais com o fato cometido pelo agente, mas é medida a partir de sua periculosidade criminal(probabilidade de voltar a delinquir), o que leva obrigatoriamente a um exame da personalidade, dos antecedentes e da conduta social, para ficarmos nestes exemplos elencados pela nossa legislação como circunstâncias judicias.

\footnotetext{
${ }^{6}$ FREITAS, Ricardo de Brito Albuquerque. As razões do positivismo penal no Brasil. Rio de Janeiro: Lumen Juris, 2002, p. 133.

${ }^{7}$ ZAFFARONI, E. Raúl. En torno de la cuestión penal. Buenos Aires: BdeF, 2005.

${ }^{8}$ FERRI, Enrico. Princípios de direito criminal: o criminoso e o crime. $2^{\mathrm{a}}$ Ed. Campinas: Bookseller, 1998, p. 201.

${ }^{9}$ Com isso, surge a famosa classificação antropológica dos criminosos, onde, inevitavelmente, o delinqüente se encaixava e que serve de diretriz básica para a sentença e execução criminal.

${ }^{10}$ FERRI, Enrico. Princípios de direito criminal: o criminoso e o crime. $2^{\mathrm{a}}$ Ed. Campinas: Bookseller, 1998, p. 201.
} 
Assim, fica claro o significado da doutrina de Hungria quando afirmara, tal como já expusemos, que a nossa legislação teria conseguido uma conciliação póstuma - alcançada apenas nos céus - entre Carrara e Ferri. Da sucinta exposição que fizemos, restou perceptível que as incompatibilidades existentes são profundas e graves, e que toda tentativa de conciliação entre tais postulados é muito mais uma forma de acentuar as suas diferenças do que conseguir uma possível harmonização entre as escolas.

\section{A CULPABILIDADE COMO ELEMENTO INTERPRETATIVO E CONDICIONANTE DAS DEMAIS CIRCUNSTÂNCIAS JUDICIAIS: A AFIRMAÇÃO DA CULPABILIDADE PELO FATO CONTRA AS INSERÇÕES PROVENIENTES DA CULPABILIDADE DO AUTOR}

Mesmo defendendo a necessidade de mudança legislativa no artigo 59 do código penal brasileiro para atender os ditames de um direito penal da culpabilidade, adequado ao contexto produzido por uma Constituição Federal que defende e preserva as garantias e direitos fundamentais do cidadão, não podemos olvidar dos problemas cotidianos que são gerados no seio das decisões jurídicas ao tratarem de tal assunto, especialmente a fundamentação inidônea ou insuficiente que ocorre na fixação da pena base, quer dizer, no exame das circunstâncias judiciais.

Acreditamos que o passo mais importante a ser tomado é entender a culpabilidade muito mais do que uma mera circunstância judicial prevista no artigo 59, que deveria ser examinada dentro de um conjunto de elementos igualmente importantes, mas, principalmente, como o principal elemento de medida e limite da sanção criminal, que condiciona, inclusive, a interpretação das demais circunstâncias aos seus ditames.

Para darmos maior concretude ao que acabamos de defender, vamos examinar os conceitos de antecedentes, conduta social e personalidade tal como eles são tratados pela doutrina tradicional - desvinculado da culpabilidade do fato -, e como imaginamos que seria a forma mais adequada de tratar tais elementos.

Os antecedentes seriam os acontecimentos do passado, importantes na análise dos aspectos positivos e negativos da vida do autor, com o intuito de fundamentar a aplicação de uma pena menor(bons antecedentes) ou exasperar uma sanção penal(maus antecedentes) ${ }^{11}$.

\footnotetext{
${ }^{11}$ SANTOS, Juarez Cirino dos. Teoria da pena. Curitiba: Lúmen Júris, 2005, p. 111.
} 
Vale asseverar que a reincidência criminal não é considerada para efeitos de maus antecedentes, uma vez que ela é uma circunstância agravante.

Diante disso, surge o questionamento sobre o que deve ser considerado como antecedentes relevantes para a individualização judicial. Temos dois posicionamentos possíveis: para a corrente extremada ou tradicional, são considerados como maus antecedentes os inquéritos instaurados e processos criminais em andamento, absolvições por insuficiência de provas, prescrições abstratas, retroativas e intercorrentes, condenações criminais sem trânsito em julgado ou que não constituem reincidência ${ }^{12}$.

A segunda corrente, denominada de crítica, afirma que só as condenações anteriores com trânsito em julgado, e que não se configuram como reincidência, são considerados maus antecedentes. E, da mesma forma que a reincidência, os maus antecedentes têm o prazo de validade de cinco anos, em virtude de uma interpretação analógica em benefício da parte ${ }^{13}$.

Esse posicionamento se fundamenta no princípio constitucional da presunção da inocência e da proibição de penas perpétuas. Vale ainda asseverar que a falta de condenações anteriores com trânsito em julgado significaria bons antecedentes, o que levaria o juiz, no momento da aplicação, reduzir o quantum da pena fixada na sentença judicial.

Em relação à definição do que seria conduta social, não podemos confundi-la com o conceito de antecedentes. Segundo Juarez Cirino a jurisprudência pátria resolveu o problema afirmando que por conduta social deve se entender o comportamento do autor do crime nos papéis de pai/mãe, marido/esposa, filho, aluno, membro da comunidade, profissional, cidadão etc. ${ }^{14}$. Além disso, diante desse conceito de conduta social, existe um problema adicional: qual seria, por exemplo, o parâmetro para afirmar se o indivíduo é ou não um bom membro da comunidade. Não existe sequer um mínimo de definição conceitual para servir de critério para uma vinculação legal.

Sobre a personalidade, cabe, de logo, uma importante advertência feita por uma pequena parcela da doutrina. Alguns autores costumam afirmar que não é possível generalizar nenhum conceito sobre personalidade, ou seja, a escolha por um dos conceitos é algo motivado pela preferência daquele que escolhe, tendo em vista que nem na psiquiatria existe sequer um mínimo de consenso sobre tal conceito ${ }^{15}$.

\footnotetext{
${ }^{12}$ CARVALHO, Amilton Bueno; CARVALHO, Salo. Aplicação da pena e garantismo. Rio de Janeiro: Lúmen Júris, 2004, p. 49.

${ }^{13}$ SANTOS, Juarez Cirino dos. Teoria da pena. Curitiba: Lúmen Júris, 2005, p. 112.

${ }^{14}$ SANTOS, Juarez Cirino dos. Teoria da pena. Curitiba: Lúmen Júris, 2005, p. 113.

${ }^{15}$ CARVALHO, Amilton Bueno; CARVALHO, Salo. Aplicação da pena e garantismo. Rio de Janeiro: Lúmen Júris, 2004, p. 55.
} 
Diante disso, tem-se uma consequência significativa. O magistrado, ao tratar sobre esse elemento, deve, em virtude da necessidade da fundamentação da decisão judicial, explicitar qual conceito de personalidade está adotando, permitindo assim a possibilidade do contraditório pela parte que se sentir prejudicada no entendimento dado pelo juiz ao valorar esse elemento.

Parece-nos indubitável que os juízes, na esmagadora maioria das vezes, além de não terem o conhecimento científico e técnico apropriado para conceituar a personalidade, sequer teriam tempo suficiente com o acusado para defini-la com a prudência necessária que exige um conceito tão fluído.

Sendo assim, lancinamos fatalmente a possibilidade de contraditar a argumentação judicial quando examina a personalidade, pois não existe na decisão qualquer menção a uma teorização sobre personalidade, como ela foi analisada e os motivos para valorá-la de forma positiva ou negativa na medida da pena.

Por outro lado, precisamos deixar claro que nos posicionamos de forma diferente ao entendimento defendido por Reale Júnior, pois, apesar de defender que as circunstâncias do artigo 59 devam ser interpretadas a partir da culpabilidade, o autor o faz de forma diferente da defendida no presente texto. Segundo o autor:

"O agente será merecedor da maior reprovação se o fato praticado revelar-se, em análise da subjetividade expressa na sua biografia, como consequência esperada de seus antecedentes, bem como de seu particular modo de ser, da sua escolha de valores e das tendências que preferiu desenvolver em detrimento de outras potencialidades positivas”16.

Esse posicionamento colacionado por Reale Júnior, mesmo que não assumido, é coerente e adequado a variante denominada culpabilidade do autor, que reprova e quantifica a pena levando em consideração o que o indivíduo é, suas características e tendências pessoais nítida influência do positivismo italiano -, deixando o fato delituoso em último plano.

É evidente que o autor concreto e individualizado do fato típico e ilícito tem importância dentro da sistemática da teoria do delito, isso não é contestado. O que se critica é o alcance que o direito penal pode fazer desse exame pessoal. E nesse ponto, como não poderia ser diferente, é o fato delituoso que dá os contornos finais e os limites para o exame do agente em concreto.

Nesse ponto, até mesmo para deixar mais clara a afirmação supracitada, colacionamos a doutrina de Zaffaroni sobre o tema tratado:

${ }^{16}$ REALE JÚNIOR, Miguel. Instituições de direito penal: parte geral. Rio de Janeiro: Forense, 2004, vol. II, p. 84. 
“As consequências práticas da ponderação da personalidade em uma culpabilidade do ato, com relação à concepção da culpabilidade do autor, são fartas de diferenças, pois o ato mais próprio da uma personalidade, aquele que já é um hábito e demanda ao homem certo esforço para conseguir se omitir, será mais reprovável - e, por fim mais punível - para a culpabilidade do autor, que não reprova o ato, e sim a personalidade inclinada ao ato, por outro lado será menos culpável para uma culpabilidade do ato, que se reprova o ato, que no âmbito de um hábito pessoal, é menos livre, pois requer um maior esforço para evitá-lo ${ }^{17 ”}$.

O pensamento do autor argentino deixa claro como podemos pensar diferente, em contraposição a doutrina tradicional, as circunstâncias judiciais do artigo 59 do código penal, interpretando-as com referência a culpabilidade do fato e não do autor. Inclusive os autores que defendem a troca da culpabilidade pela prevenção geral positiva como critério para medida da pena criticam a utilização da personalidade, já que a conclusão não poderia ser diferente da já exposta por Zaffaroni ${ }^{18}$.

Tomemos um exemplo muito corriqueiro nos dias atuais e que serve perfeitamente para ilustrarmos o nosso posicionamento. Imaginemos que um viciado em drogas, com o intuito de manter o seu vício e sem nenhuma pretensão de deixá-lo, começa a traficar, por exemplo, maconha. Se pegarmos a doutrina de Reale como parâmetro, uma pena elevada não seria difícil de justificar, pois o que se reprova é a personalidade do indivíduo, as suas escolhas valorativas, e o seu próprio ser.

Diametralmente oposta seria a conclusão se optarmos por uma culpabilidade do fato, tal como defendemos e se encontra exposta na citação de Zaffaroni. Nesse caminho, o exame sobre o autor é limitado e somente se justifica dentro do contexto do fato delituoso, trazendo uma resposta totalmente diferente da acima tratada. Analisando o fato delituoso - tráfico de drogas - e o autor do crime - indivíduo viciado que age para manter o próprio vício -, fica claro que, reprovando a ação do agente, a sua pena nunca poderia ser alta tendo em vista que o vício retira dele uma parcela significativa da sua capacidade de se determinar de forma diferente, melhor dizendo, a sua capacidade de se comportar conforme o direito(elemento central do conceito de culpabilidade) é visivelmente diminuta quando tomamos como

\footnotetext{
17 ZAFFARONI, Eugenio Raúl. Tratado de derecho penal: parte general. Buenos Aires: Ediar, 1988, vol. V, p. 307.

${ }^{18}$ HAFFKE, Bernhard. Reincidencia y medición de la pena. In: SCHÜNEMANN, Bernd (Org.). El sistema moderno del derecho penal: cuestiones fundamentales. Buenos Aires: BdeF, 2012, p. 242.
} 
parâmetro um agente que realiza a mesma conduta de tráfico de maconha sem, no entanto, ser motivado pelo vício em drogas.

\section{CONCLUSÃO}

Não há dúvidas que o nosso artigo 59 do código penal é uma construção legislativa dotada de várias dificuldades, como já sugerida por Hungria ao tratar sobre o tema. A tentativa improfícua de ajustar os postulado da Escola Clássica e da Escola Positiva possibilitou a manutenção de elementos adequados a uma culpabilidade do autor, que valora a aplicação da pena levando em consideração circunstâncias que se afastam do fato delituoso, mas que se adequam ao ser do agente.

Idealmente falando, acreditamos que a melhor solução seria a exclusão dos elementos de influencia do positivismo italiano, como - para ficarmos nas circunstâncias examinadas os antecedentes e a conduta social, uma vez que em nada se referem ao fato delituoso, e sim ao peculiar modo de ser do indivíduo condenado. Fica claro que a referência a tais elementos ainda fere o Estado Democrático de Direito, além da forma já referida, no momento que o julgador agrava a pena alegando uma suposta falta de socialização do condenado, por não ter, por exemplo, uma boa relação com os vizinhos e os colegas de trabalho. Nada há de democrático num direito penal que intervém coativamente no modo de ser do agente, como se existisse, unicamente, "um modo de ser".

Contudo, esperar uma modificação legislativa é quimérico em demasia. Por isso, alertamos para a necessidade de se interpretar as circunstâncias constantes no artigo 59 do código penal a partir da culpabilidade do fato, que valora a ação delituosa engendrada pelo agente. Essa interpretação é coerentemente adequada aos valores estabelecidos na nossa Constituição Federal de 88 e, por conseguinte, ao Estado Democrático de Direito.

\section{REFERÊNCIAS}

CARRARA, Francesco. Programma del Corso di Diritto Criminale: Parte Generale. Lucca: Tipografia Giusti, 1889, vol. I.

CARVALHO, Amilton Bueno; CARVALHO, Salo. Aplicação da pena e garantismo. Rio de Janeiro: Lúmen Júris, 2004. 
FERRI, Enrico. Princípios de direito criminal: o criminoso e o crime. $2^{\mathrm{a}}$ Ed. Campinas: Bookseller, 1998.

FREITAS, Ricardo de Brito Albuquerque. As razões do positivismo penal no Brasil. Rio de Janeiro: Lumen Juris, 2002.

HAFFKE, Bernhard. Reincidencia y medición de la pena. In: SCHÜNEMANN, Bernd (Org.). El sistema moderno del derecho penal: cuestiones fundamentales. Buenos Aires: BdeF, 2012. HUNGRIA, Nelson. Comentários ao código penal. Rio de Janeiro: Revista Forense, 1955, vol. V.

REALE JÚNIOR, Miguel. Instituições de direito penal: parte geral. Rio de Janeiro: Forense, 2004, vol. II.

SANTOS, Juarez Cirino dos. Teoria da pena. Curitiba: Lúmen Júris, 2005.

SCHÜNEMANN, Bernd. La función del principio de culpabilidad en el derecho penal preventivo. In: SCHÜNEMANN, Bernd (Org.). El sistema moderno del derecho penal: cuestiones fundamentales. Buenos Aires: BdeF, 2012.

ZAFFARONI, E. Raúl. En torno de la cuestión penal. Buenos Aires: BdeF, 2005.

ZAFFARONI, Eugenio Raúl. Tratado de derecho penal: parte general. Buenos Aires: Ediar, 1988, vol. V. 